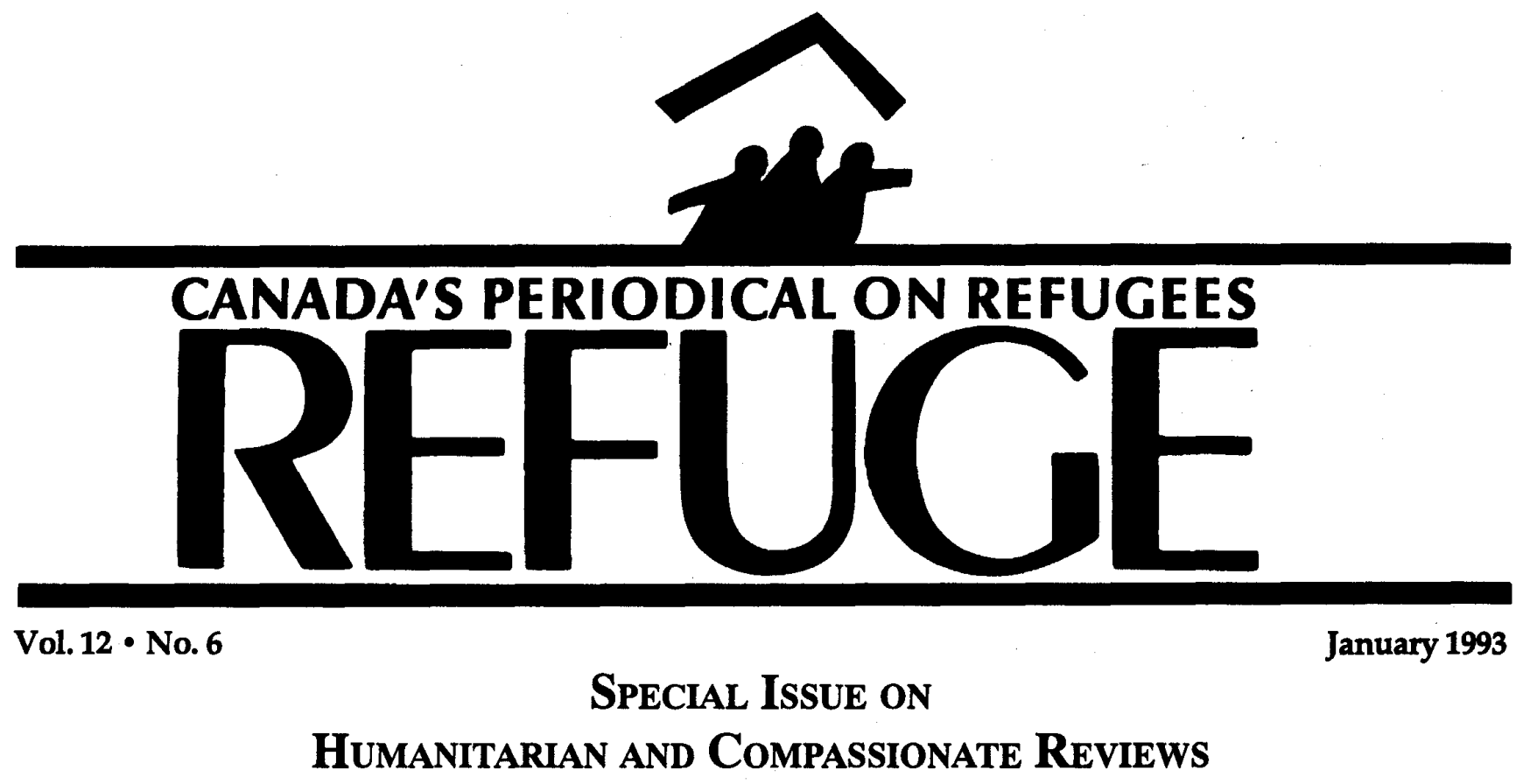

\title{
The Review of Rejected Refugee Claims
}

According to federal government estimates published in December 1992, approximately 9,100 refused refugee claimants' cases were reviewed between January 1989 and October 1992. Of these cases, 8,800 were negative decisions and 300 were positive decisions. These 300 individuals represent 3.2 percent of all cases reviewed. The low acceptance rate at the postclaim review level could be a testament to the accuracy in determination at the board level, or it could indicate a reluctance to find otherwise than predecessors, or a misunderstanding of the substantive criteria of a review. It is not surprising that there was great concern about this informal postclaim review process and that its integrity was questioned. The overriding impression of refugee advocates was that the postclaim review process did not accommodate a situation in which fresh evidence surfaced after a determination was made by the board, or in which a change in country conditions occurred or in which a candid reading of humanitarian and compassionate considerations would be found meritorious.
It was in this environment that the Centre for Refugee Studies, in conjunction with refugee advocates, nongovernmental organizations and government representatives, convened to examine the postclaim review process and to determine how it could be made a more transparent and meaningful procedure.

It is obvious that there is great confusion at all levels of representation about the rationale for, limits and objectives of any postclaim review for those refugee claimants who were not determined to meet the Convention refugee definition. The review process at this stage in a person's claim to remain in Canada is seemingly misunderstood by refugee advocates and government officials alike. It is simultaneously referred to as a humanitarian and compassionate review, a postclaim review and a preremoval review. Clearly, some definition was needed as to what review options were available to a claimant, their scope and any procedures associated with that review. It is evident that there is always a right for a refugee claimant, among others, to ask for consideration under Section 114(2) of the Immigration Act. This section and accompanying policy guidelines indicate that consideration will be given to the enumerated humanitarian and compassionate factors that would lead the minister of Employment and Immigration's repre-

\section{Contents:}

The Review of Rejected Refugee Claims, Guest Editorial .................. 1

Workshop on Review of Rejected Refugee Claims .......................... 3

Extract from New Immigration Regulations, re Bill C-86 .................. 24 


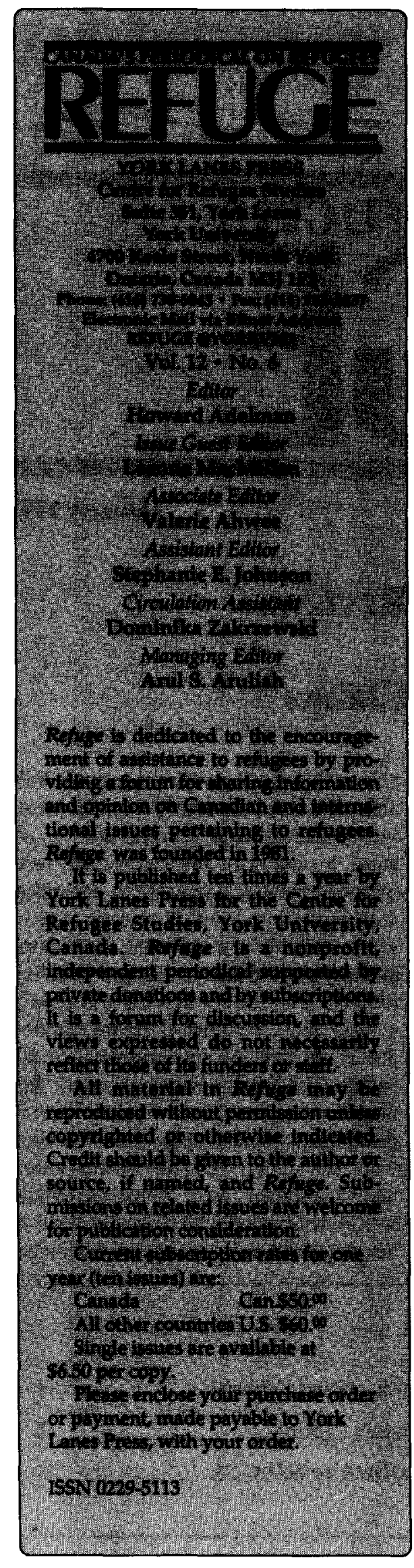

sentative to exercising discretion favourably and to grant landed immigrant status to the applicant. There is a need for this sort of mechanism in any determination process in order to address public policy situations. However, the scope of the policy is limited to those situations that are compelling for a limited set of reasons.

The review mechanisms specifically available after a refugee claim has been denied include the file review done immediately after the Convention Refugee Determination Division renders a negative decision. This review is done by Canada Immigration Centres and is based on the officer's review of the main facts in the file, recent country information and

\section{For refugee claimants from countries where there is civil strife and generalized oppression-countries to which the failed refugee claimant cannot yet be re- turned-there is still no satisfactory remedy.}

submissions from counsel. Decisionmaking is based on the standard of "unduly harsh or inhumane treatment if the claimant were to be returned to his or her country of origin." If the claimant is not accepted at this level, then the file will be referred to the Central Removals Unit of Immigration for a preremoval review and in order to prepare the failed refugee claimant for return to the country of origin. The refugee claimant can make representations to the government at any time during this review process. However, the removals proceedings will not be halted pending submissions by the claimant.

There has been much confusion about the decision-making criteria for these sorts of reviews and the types of factors that the decision-maker would take into account. This was partly due to the informal nature of the proceedings and a tension as to the reading of the actual country conditions and the safety of return. However, with Bill C-86, it is now very clear that the criteria are solely that of individuated, identifiable risk if the claimant was forced to leave Canada. This is not the "humanitarian and compassionate" type of postclaim review as it was widely understood to be-it is a review based on very limited criteria (some would argue more difficult criteria to meet than for the Convention refugee definition and perhaps an inappropriate standard, given that the board is less likely to make an error regarding the relevance of individuated risk than it is to misconstrue the relevance of generalized forms of risk).

The Immigration Regulations, 1978Amendments in consequence of Bill C-86 will now provide the decision-making criteria for the postdetermination of refugee claimants. Indeed, the regulations are an effort to eliminate the confusion about the whole postdetermination process and to codify the informal practices that had developed since the decentralization of postclaim reviews. According to the amendments, the risk must be personal, that is, directed at the individual rather than based on generalized situations of risk faced by other individuals in the country of return. It must be compelling, consisting of a threat to life, excessive sanctions or inhumane treatment.

For refugee claimants from countries where there is civil strife and generalized oppression-countries to which the failed refugee claimant cannot yet be returned-there is still no satisfactory remedy. The only likely remedy is for the creation of a designated class or other special program. The practical effect of the postdetermination standard (under which so few claimants succeed) is that in cases that involve countries to which persons cannot be removed, the claimants must wait in Canada in a state of limbo. Since they are not in status refugee claimants, they do not accrue any rights to work or to public assistance. They are engaged in a waiting game, one where the conditions in their countries of origin must improve to a degree where they can be returned.

It should be remembered that no system of determination is free of mistakes 